Document downloaded from:

http://hdl.handle.net/10251/83828

This paper must be cited as:

Holzem, KM.; Gómez García, JF.; Glukhov, AV.; Madden, EJ.; Koppel, AC.; Ewald, GA.; Trenor Gomis, BA.... (2016). Reduced response to IKr blockade and altered hERG1a/1b stoichiometryin human heart failure. Journal of Molecular and Cellular Cardiology. 96:82-92. doi:10.1016/j.yjmcc.2015.06.008.

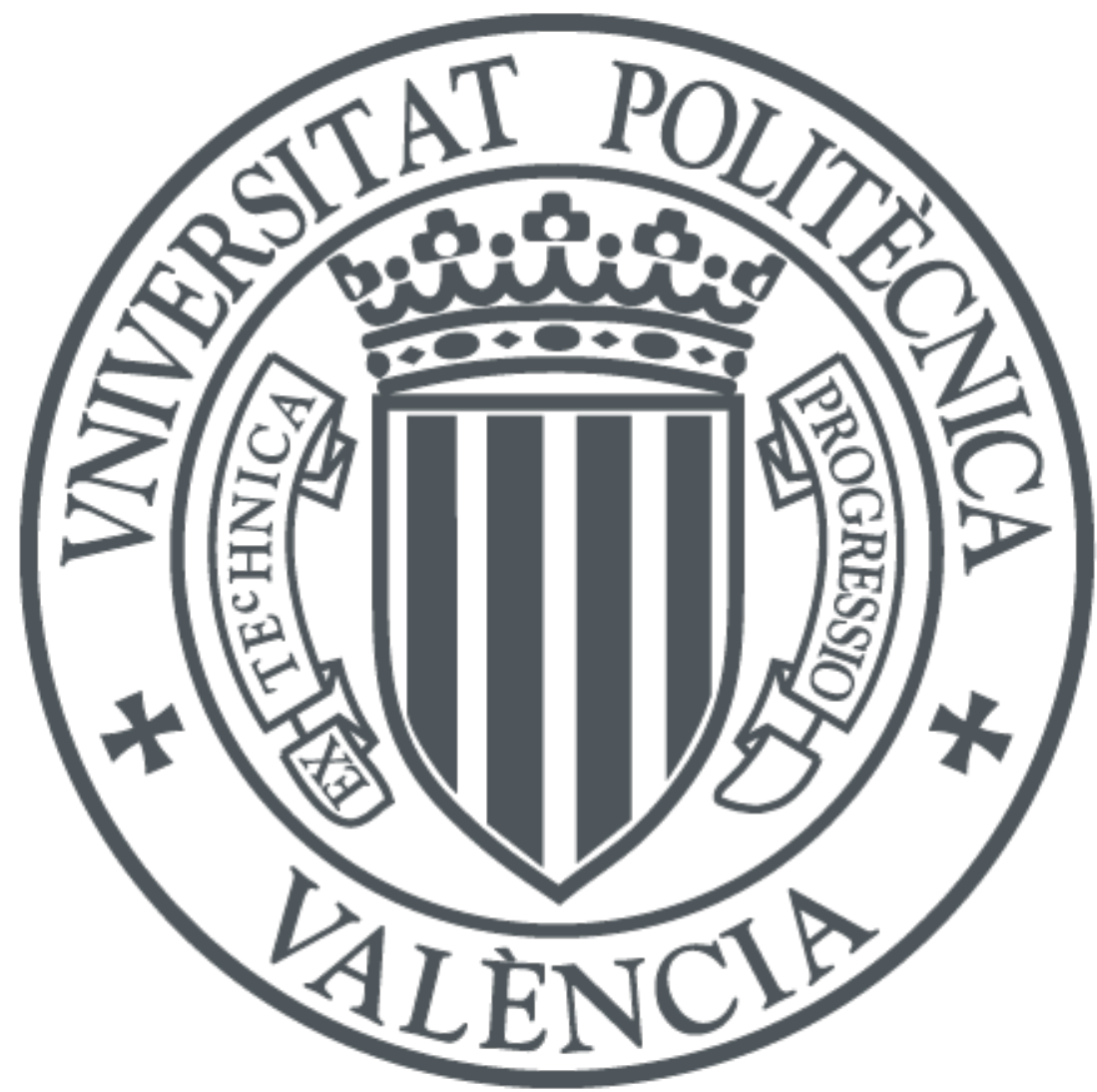

The final publication is available at

http://dx.doi.org/10.1016/j.yjmcc.2015.06.008

Copyright Elsevier

Additional Information 


\section{Diminished Response to $\mathrm{I}_{\mathrm{kr}}$ Blockade and Altered hERG1a/1b Stoichiometry in Human Heart Failure}

2

3 Katherine M. Holzem, M.S. ${ }^{1}$, Juan F. Gomez ${ }^{2}$, Alexey V. Glukhov, Ph.D. ${ }^{1}$, Eli J. Madden ${ }^{1}$, Aaron C. Koppel ${ }^{1}$,

4 Gregory Ewald, M.D. ${ }^{1}$, Beatriz Trenor, Ph.D. ${ }^{2}$, Igor R. Efimov, Ph.D. ${ }^{1,3}$

5

6 Affiliations:

$7 \quad{ }^{1}$ Department of Biomedical Engineering, Washington University in St. Louis, MO 63130, USA.

$8 \quad{ }^{2}$ Polytechnic University of Valencia, Valencia, Spain

$9{ }^{3}$ Moscow Institute of Physics and Technology, Dolgoprudny, Moscow Region, Russia

10

11

12 Corresponding author:

13 Igor R. Efimov

14 Department of Biomedical Engineering

15 Washington University in Saint Louis

16 390E Whitaker Hall

17 One Brookings Drive

18 St. Louis, Missouri 63130-4899

19 Tel: 1-314-935-8612; Fax: 1-314-935-8377;

20 E-mail: igor@wustl.edu

21

22

23

24

25

26 


\section{Abstract}

29 Rationale: Heart failure (HF) claims 250,000 lives per year in the US, and nearly half of these deaths are

30 sudden and presumably due to ventricular tachyarrhythmias. QT interval and action potential (AP)

31 prolongation is a hallmark proarrhythmic change in the failing myocardium, which potentially results

32 from alterations in repolarizing potassium currents. Thus, we aimed to examine whether decreased

33 expression of the rapid delayed rectifier potassium current, $I_{\mathrm{Kr}}$, contributes to repolarization

34 abnormalities in human HF. To map functional $\mathrm{I}_{\mathrm{kr}}$ expression across the left ventricle (LV), we optically

35 imaged coronary-perfused LV free wall from donor and end-stage failing human hearts. The LV wedge

36 preparation was used to examine transmural AP durations at $80 \%$ repolarization (APD80), and treatment

37 with the $\mathrm{I}_{\mathrm{Kr}}$-blocking drug, E-4031, was used to interrogate functional expression. We assessed the

38 percent change in APD80 post-I kr $_{\text {b }}$ blockade relative to baseline APD80 ( $\triangle$ APD80) and found that $\triangle A P D 80$ s

39 are reduced in failing versus donor hearts in each transmural region, with 0.35-, 0.43-, and 0.41-fold

40 reductions in endo-, mid-, and epicardium, respectively ( $p=0.008,0.037$, and 0.022 ). We then assessed

41 hERG1 isoform gene and protein expression levels using qPCR and Western blot. While we did not

42 observe differences in $h E R G 1 a$ or $h E R G 1 b$ gene expression between donor and failing hearts, we found

43 reductions in hERG1a mature protein and a shift in the hERG1a:hERG1b isoform stoichiometry.

44 Computer simulations were then conducted to assess $\mathrm{I}_{\mathrm{Kr}}$ block under E-4031 influence in failing and

45 nonfailing conditions. Our results confirmed the experimental observations and E-4031-induced relative

46 APD80 prolongation was greater in normal conditions than in failing conditions, provided that the

47 cellular model of $\mathrm{HF}$ included a significant downregulation of $\mathrm{I}_{\mathrm{K}}$.

48 Conclusions: In human $\mathrm{HF}$, the response to $\mathrm{I}_{\mathrm{Kr}}$ blockade is diminished, suggesting decreased functional $\mathrm{I}_{\mathrm{Kr}}$

49 expression This reduced functional response is associated with altered hERG1a:hERG1b protein

50 stoichiometry in the failing human LV, and failing cardiomyoctye simulations support experimental

51 findings. Thus, $\mathrm{I}_{\mathrm{kr}}$ protein and functional expression may be important determinants of repolarization

52 remodeling in the failing human LV.

54 Key Words: Heart failure, arrhythmias, potassium channels, remodeling, repolarization

56 Abbreviations 
$\mathrm{AP}=$ Action Potential; $\mathrm{APD}=$ Action Potential Duration; APD80=Action Potential Duration at $80 \%$

58 Repolarization; D=Donor; Endo=Endocardium; Epi=Epicardium; HF=Heart Failure; F=Failing; LV=Left

59 Ventricle; Mid=Midmyocardium.

\section{Introduction}

Heart failure (HF) is the end stage of many cardiovascular diseases, in which the heart can no longer support the metabolic demands of the body. HF is an increasing problem in the US, with an estimated 5 million Americans currently afflicted by the disease. Approximately $1 / 4$ million HF-related deaths occur annually,[1] nearly half of which are due to sudden cardiac death. These sudden cardiac events are presumably the result of ventricular tachyarrhythmias, which are a consequence of adverse electrophysiologic remodeling during the HF progression.

Action potential (AP) prolongation and resulting QT prolongation are hallmark arrhythmogenic changes in the failing myocardium.[2-5] While increased late sodium current has been demonstrated in association with AP prolongation in $\mathrm{HF},[6-8]$ voltage-dependent potassium currents are critical determinants of cardiac AP duration (APD). In humans, the rapid component of the delayed rectifier potassium current $\left(\mathrm{I}_{\mathrm{Kr}}\right)$ is largely responsible for ventricular repolarization. Tetramers of the $h E R G 1$ protein $\alpha$-subunit, encoded by the $K C N H 2$ gene, form the channel underlying cardiac $I_{\mathrm{kr}}$. Two different splice variants of $K C N H 2$, both $h E R G 1 a$ and $h E R G 1 b$, are expressed in human ventricular tissue, with the hERG1a isoform predominating.[9] In various animal models of HF, delayed rectifier potassium currents are reduced. However, in human isolated cardiomyocytes, $\mathrm{I}_{\mathrm{kr}}$ amplitude is small, making differences between donor and failing hearts undetectable.[2]

We hypothesized that $\mathrm{I}_{\mathrm{Kr}}$ is downregulated in human $\mathrm{HF}$, promoting AP prolongation in failing myocardial tissue. Thus, we aimed to investigate functional $I_{k r}$ expression in the failing human left ventricle (LV) and examine the relative expression of hERG1a and hERG1b isoforms at the gene and protein expression levels. We then conducted cellular and fiber simulation studies to provide further

83 evidence for $I_{\mathrm{kr}}$ downregulation in HF. The regulation of functional $\mathrm{I}_{\mathrm{kr}}$ in human HF has not been

84 previously reported; thus, these studies may help elucidate the underpinnings of arrhythmogenic AP 85 prolongation in the failing human heart.

\section{Materials and Methods}


Human heart recovery. All studies using human heart tissue have been approved by the Institutional

90 Review Board at Washington University in St. Louis. In total for this study, we recovered 16 donor

91 human hearts, rejected for transplantation from the Mid America Transplant Services (St. Louis, MO),

92 and 14 end-stage failing hearts from transplant recipients at Barnes-Jewish Hospital. All hearts were

93 obtained immediately after removal from the chest in the operating room. Hearts were arrested using

94 ice-cold cardioplegic solution and transported to the laboratory for dissection and functional

95 experiments. Prior to experiments, LV tissue was collected and preserved in RNA later (Sigma-Aldrich, St.

96 Louis, MO) for mRNA or flash-frozen in liquid nitrogen for protein expression analyses.

Optical imaging. Human LV wedge preparations were used for electrophysiologic experiments, as

99 described previously.[3] Briefly, wedges were dissected from an LV marginal branch and were mounted

100 with the transmural surface facing the optical apparatus (Figure 1A-B). Preparations were perfused with

101 oxygenated Tyrode's solution maintained at $37^{\circ} \mathrm{C}$, with a perfusion pressure of $60-80 \mathrm{mmHg}$.

102 Blebbistatin (10-20 $\mu \mathrm{M})$ was used to immobilize myocardial tissue, and Di-4-ANEPPS was used to map

103 transmembrane potential. Pseudo-ECGs were recorded with $\mathrm{Ag} / \mathrm{AgCl}$ electrodes placed on either side of

104 the transmural surface, and human intracellular APDs were validated using fixed $3.0 \mathrm{M} \mathrm{KCl}$ filled

105 microelectrodes. Tissue was paced using a steady state S1S1 restitution protocol, starting at a pacing

106 cycle length $(\mathrm{CL})$ of 2,000 ms and progressively decreasing to the functional refractory period. Data were

107 analyzed using custom-written MATLAB software.[10] Table 1 shows donor and patient characteristics

108 of hearts used in functional experiments.

109

110 Pharmacologic interrogation of $I_{k r}$. Following the collection of baseline restitution measurements, we

111 added $1 \mu \mathrm{M}$ E-4031, a high-affinity $I_{\mathrm{Kr}}$ blocker, to the Tyrode's solution. Recordings were collected at 5-

112 minute intervals after drug treatment, until a steady-state AP morphology was achieved (approximately

113 15-20 minutes). The steady state restitution protocol was then repeated (Figure 1C). Because E-4031

114 blockade of $I_{\mathrm{kr}}$ is essentially irreversible, we did not conduct drug washout. 
A

RNA isolation and real-time qPCR. Total RNA was extracted from human LV tissue samples using the

RNEasy Fibrous Tissue Mini Kit (Qiagen, Valencia, CA), and RNA yield was quantified and purity assessed using the Nandrop 1000 (Thermo Scientific), as previously described.[11] Total RNA (1-2 ug) was converted to cDNA using the High Capacity cDNA Reverse Transcription Kit (Applied Biosystems, Foster

124 genes for cardiac gene expression studies.[12] The TaqMan Gene Expression Assay Hs00165120_m1 was

125 used to detect $h E R G 1 a$ mRNA, and custom-made assays were used for the detection of $h E R G 1 b$, as

126 previously described.[12] Data were analyzed using the threshold cycle (Ct) relative quantification

127 method.[11, 13]

129 Protein expression. Western blot analysis was performed on LV protein lysates, as previously

130 described. [3, 4] Fresh endocardial and epicardial tissues were frozen in liquid nitrogen, pulverized, and 
131 homogenized in super RIPA buffer. Protein was quantified using the BCA Assay (Bio-Rad, Hercules, CA),

132 and equal protein masses were loaded for each sample. SDS-PAGE was carried out using standard

133 methods, and membranes were probed with anti-Kv11.1 antibodies (Alomone, Israel, Jerusalem; Enzo

134 Life Sciences, Farmingdale, NY). Images were acquired with the LAS-4000 mini (Fujifilm, Tokyo, Japan)

135 and analyzed with Multi Gauge software (Fujifilm, Tokyo, Japan). Protein band densities were

136 normalized to GAPDH.

Statistical analysis. Statistical significance was determined by Student's t-test or Welch's t-test. Both one- and two-tailed t-tests were used as appropriate, depending on the whether our experimental prediction indicated a unidirectional change or that the alteration may have occurred in either direction.

141 Paired t-tests were used to compare the same hearts before and after drug treatment, and unpaired 142 tests were used to analyze donor and failing heart groups. The Welch's t-test was selected when a 143 statistically significant $p$ value from $f$-test $(p<0.05)$ indicated unequal variance between groups.

Human ventricular cell AP modeling. Simulations of endocardial and epicardial cell electrophysiological activity were carried out using one of the most up-to-date human ventricular myocyte models developed by Grandi et al.[14] (GPB model), which was characterized by a thorough description of

148 intracellular calcium handling. Both cellular and one-dimensional strand simulations were performed, 149 and we computed APD at 80\% repolarization (APD80). A steady state S1S1 restitution protocol was 150 simulated, starting at a pacing cycle length $(C L)$ of 2,000 ms and decreasing to the functional refractory period. Computational methods are detailed in the Supplementary Materials.

153 Homogeneous electrophysiological remodeling in HF. To simulate the electrical activity of human failing

154 ventricular myocytes, the GPB model was modified as in Trenor et al.[15] lonic parameters were

155 changed to describe the hallmark characteristics of failing cardiac tissues and cells, such as AP

156 prolongation and alterations of calcium handling, on the basis of experimental data (see Table 2 for

157 details). To model downregulation of $I_{\mathrm{kr}}$, we gradually decreased this current up to $90 \%$ in different 158 simulations.

160 Heterogeneous electrophysiological remodeling in HF. Experimental studies describing transmural ion 161 channel expression changes are insufficient from the failing human heart, and most of these studies 162 have been limited to mRNA or protein level investigation.[11, 16-18] Furthermore, extrapolating gene or 
163 protein expression to channel functional activity is not trivial. Thus, on the basis of the limited literature,

164 we included a heterogeneous model of HF based on Gomez et al., where certain parameters were

165 selectively altered in epicardial and endocardial cells.[19] Specifically, the activity of the $\mathrm{Na}^{+} / \mathrm{Ca}^{2+}$

166 exchanger $\left(I_{N C X}\right)$, which shows a significant upregulation in failing myocytes, was increased 2-fold in

167 epicardial cells and 1.6-fold in endocardial cells. [18, 20-22] As reported in our experiments, $I_{\mathrm{kr}}$ was also

168 decreased heterogeneously in endocardium (50\% reduction) and epicardium (60\% reduction) in strand

169 simulations.

170

\section{Results}

172

173 APD Restitution with $I_{k r}$ blockade. To examine transmural effects of $I_{\mathrm{kr}}$ expression in the human LV, we

174 measured optical APs before and after treatment with E-4031. We then analyzed APD80 for each

175 transmural region and constructed APD80 restitution curves by plotting the APD80 duration against the

176 pacing cycle length (PCL) for donor and failing hearts. Baseline APD80 restitution curves for donor hearts

177 (Figure 2A) reveal greater transmural dispersion of APD80s and shorter APs compared with failing hearts

178 (Figure 2B). The longer APs in the failing heart are more pronounced at lower pacing frequencies,

179 leading to steeper restitution curves. In contrast, following E-4031 treatment, APD80s for failing hearts

180 (Figure 2E) are shorter than those for donor hearts (Figure 2D) at each pacing cycle length and

181 restitution curves for failing hearts appear flattened (Figure 2B). APD80 gradients were then calculated

182 at several PCLs by subtracting APD80 Endo-APD80 $0_{\mathrm{Epi}}$. Transmural dispersion of APD80s was observed for

183 donor hearts without and with E-4031, but not for failing hearts under either condition (Figure 2C,F). In

184 addition, the donor heart APD80 gradients demonstrated a linear relationship with $P C L\left(R^{2}=0.92, p=\right.$

1850.003 for baseline; $R^{2}=0.78, p=0.02$ for $E-4031$ ), while no relationship was observed between failing

186 heart APD80 gradients and PCL (Figure 2C,F). 
A

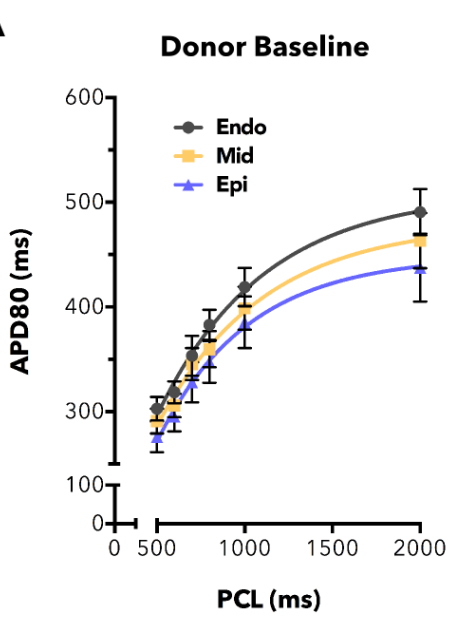

D

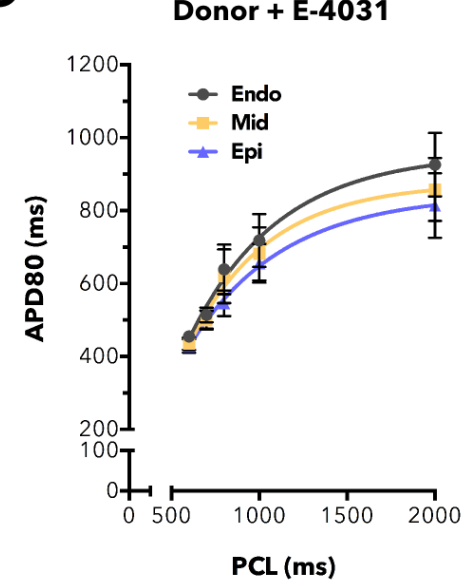

B

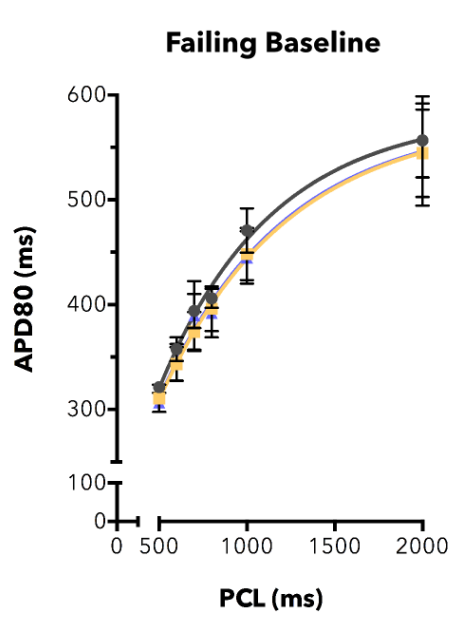

$\mathbf{E}$

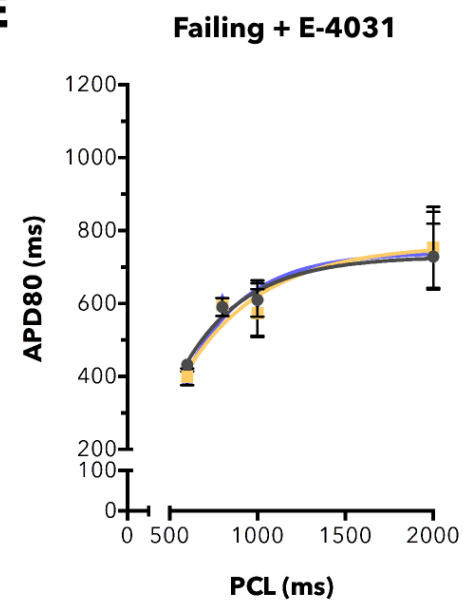

C

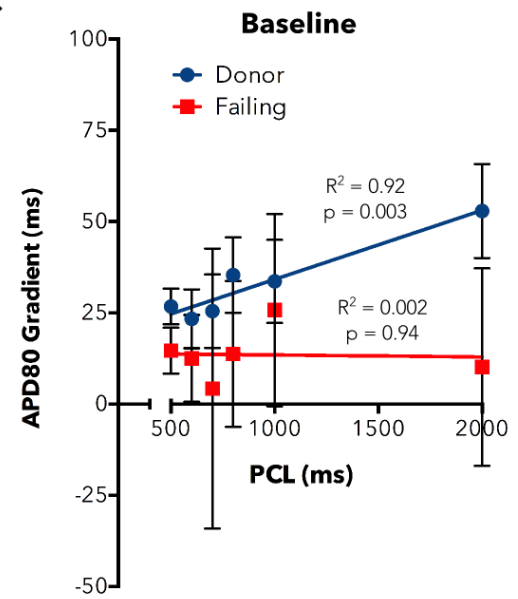

$\mathbf{F}$

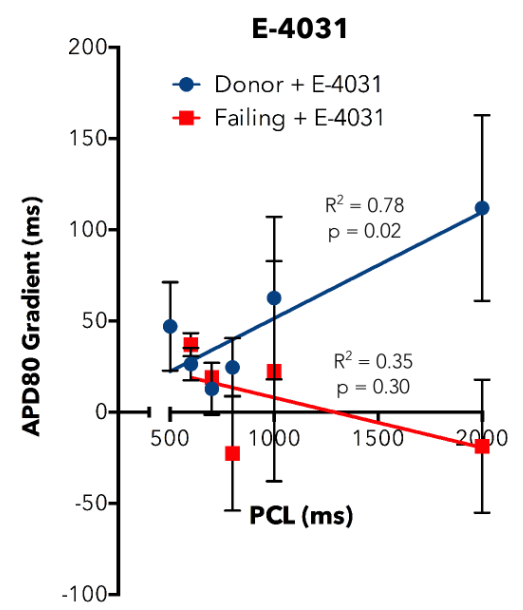

189 Functional $I_{k r}$ expression. To assess functional, cell-surface expression of $I_{k r}$, we examined APD80

190 prolongation following E-4031 treatment. Figure 3A,B shows APD80 maps for representative donor and

191 failing human hearts, respectively, at 1000 ms PCL. Corresponding pseudo-ECG recordings and optical

192 recording traces are shown below each map. APD80 maps for the donor heart show the normal APD

193 gradient from endo- to epicardium, and significant prolongation of the APD in each transmural region

194 with $\mathrm{I}_{\mathrm{kr}}$ blockade. Conversely, the transmural distribution of APD80 are more uniform in the failing heart

195 under control conditions, consistent with our previous reports. $[3,23]$ However, the effect of $I_{\mathrm{Kr}}$ blockade on transmural APD80s appears reduced. 
A

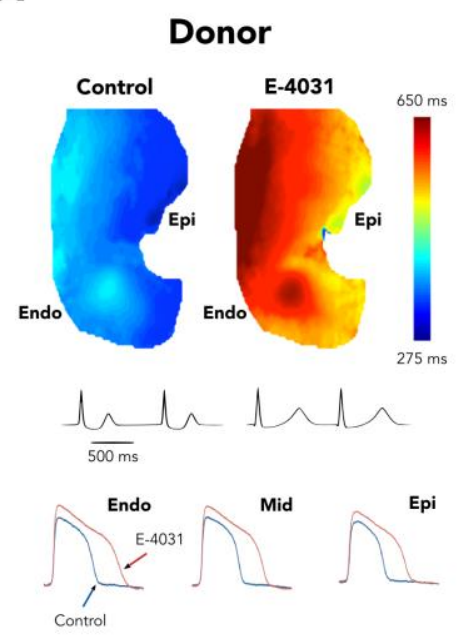

B

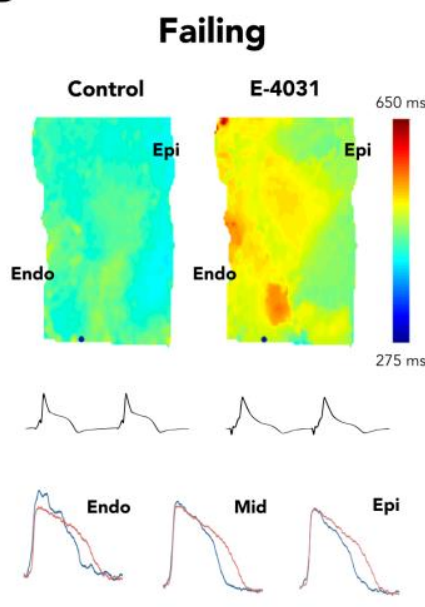

E

197

The distribution of APD80s is varied between donor and failing hearts without and with $\mathrm{I}_{\mathrm{kr}}$ blockade. Figure 3C,D show APD80 Gaussian distribution curves computed from the means and pooled standard deviations for donor and failing hearts. The distribution curves demonstrate greater separation between the pre- and post-E-4031 conditions for donor hearts compared with failing hearts. This widening between curves is due to the higher baseline APD80s in failing hearts, but even more so from increased APD80s in donor hearts following $I_{\mathrm{kr}}$ blockade. Figure 3E shows average APD80 values for donor and failing hearts under control conditions and with E-4031 treatment (PCLs $=1,000 \mathrm{~ms}$ ). $\mathrm{I}_{\mathrm{kr}}$ blockade in donor hearts results in strongly significant $(p<0.01)$ increases in APD80 in each transmural region; however, while $\mathrm{I}_{\mathrm{kr}}$ blockade still leads to transmurally increased APD80s for failing hearts, the differences are less significant $(p<0.05)$. In addition, we calculated the \% change in APD80 after E-4031 treatment relative to the control condition, or $\triangle \mathrm{APD} 80=\left[\left(\mathrm{APD} 80_{\mathrm{E}-4031}-\mathrm{APD} 80_{\text {Control }}\right) / \mathrm{APD} 80_{\text {control }} * 100\right.$, which are greater in the donor hearts for each transmural region. $\triangle$ APD80 values for failing versus donor hearts demonstrate $0.43-, 0.40-$, and 0.45 -fold reductions in endo-, mid-, and epicardium, respectively 
$212(p=0.020, p=0.033, p=0.013$, Figure 3F). Results obtained at the $2,000 \mathrm{~ms} P C L$ were consistent with the 1

$213 \mathrm{~Hz}$ data and are displayed in Figure S1.

214

$215 K C N H 2$ Gene Expression. To examine whether transcriptional regulation of $h E R G 1 a$ and $h E R G 1 b$ splice

216 variants is responsible for the reduced effect of E-4031 in failing hearts, we analyzed the mRNA

217 expression of both variants in human LV tissue samples. Figure $4 A, B$ show relative quantification values

218 of $h E R G 1 a$ and $h E R G 1 b$ in donor and failing LV samples. We found no statistically significant differences

219 in the mRNA expression levels when comparing failing to donor human heart tissue $(p=0.84$ and $p=$

2200.36 , respectively). Although, $h E R G 1 b$ appears reduced in $\mathrm{F}$, the variance for $h E R G 1 b$ donor gene

221 expression is large. The majority of the apparent difference in $h E R G 1 b$ expression was due to a single

222 sample, which was not excluded by Grubb's analysis. These results suggest that decreased functional $\mathrm{I}_{\mathrm{Kr}}$

223 in $\mathrm{HF}$ is not due to altered $K C N H 2$ gene expression or splicing.

225 hERG1 Protein Expression. Given that post-translational protein processing regulates functional ion

226 channel expression, we then investigated whether altered hERG1 protein expression was associated

227 with functional $I_{\mathrm{Kr}}$ downregulation. To do this, we examined hERG1a and hERG1b protein expression

228 levels in endo- and epicardial LV samples. We observed that normalized hERG1a mature protein had a

2290.55 -fold reduction $(p=0.51)$ in the epicardium of failing compared with donor hearts (Figure 4D), and

230 total hERG1a protein trended toward reduction (Figure 4C). In addition, the stoichiometry of the

231 hERG1a:hERG1b isoforms was altered in failing versus donor hearts, with 0.52 - and 0.58-fold reductions

232 in the endocardium and epicardium, respectively $(p=0.012$ and $p=0.019$, Figure $4 G)$. Interestingly,

233 hERG1b did not appear altered in failing hearts (Figure 4E,F); however, there was a trend toward

234 increased expression of the immature hERG1b isoform in failing hearts (Supplementary Figure S3).

235 hERG1b data were confirmed by experiments with an alternative antibody and are shown in the

236 supplementary data (Figure S4). 
A

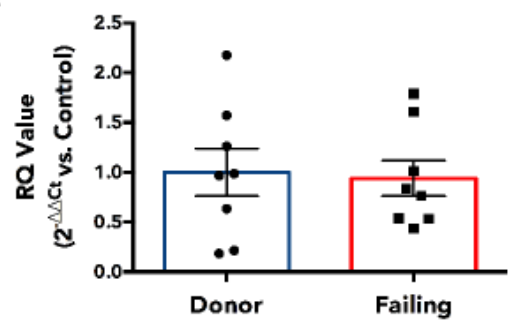

C

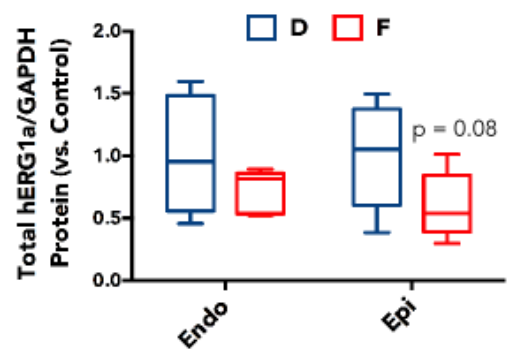

E

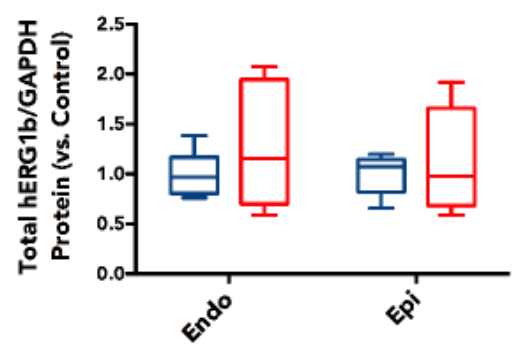

G

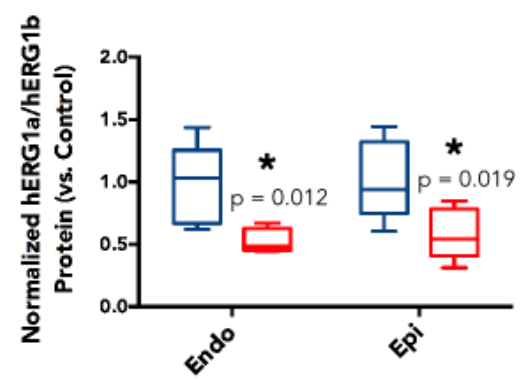

B

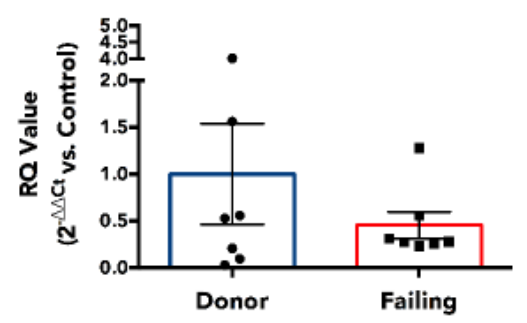

D

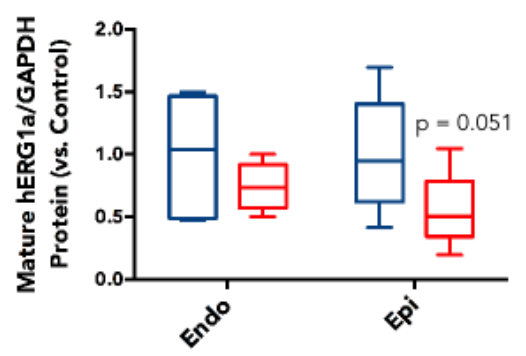

F

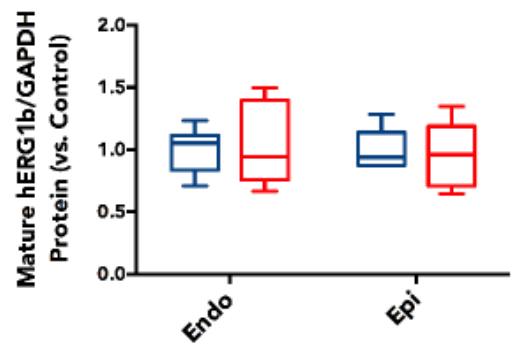

H

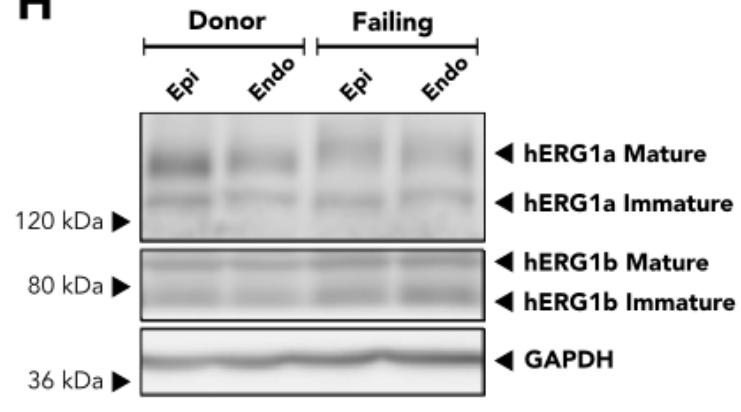

Computer simulation of myocyte $I_{k r}$ blockade. The effects of E-4031 were tested in isolated virtual nonfailing and failing endocardial myocytes. To simulate the effects of the drug, $I_{\mathrm{kr}}$ conductance was reduced by $90 \%$ in nonfailing myocytes and by $90 \%$ or $70 \%$ in failing myocytes. Based on experimentally

243 determined protein expression levels, with a stoichiometric shift from hERG1a to hERG1b, we assumed

244 that the effect of the drug could be weaker in failing myocytes. Homotetrameric hERG1a channels have

245 differential sensitivity to $\mathrm{I}_{\mathrm{kr}}$-blocking drugs compared with hERG1a-hERG1b heteromeric channels, with hERG1a-hERG1b channels being less sensitive to E-4031.[24] 
A

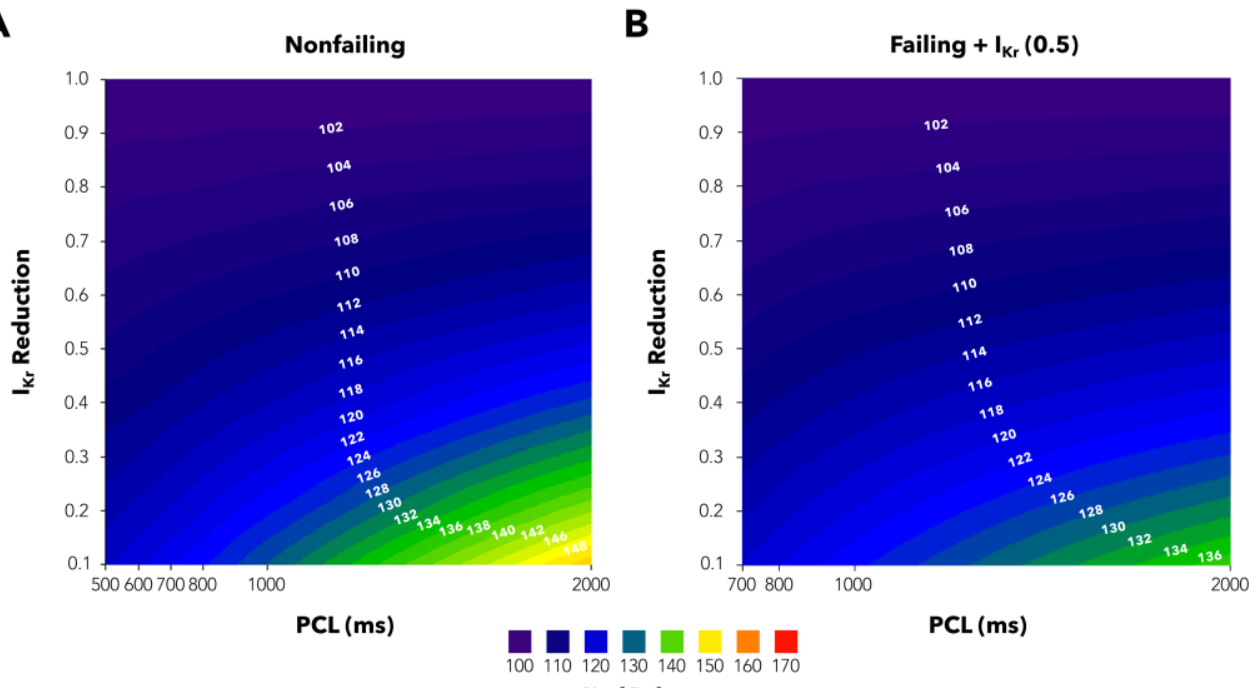

C

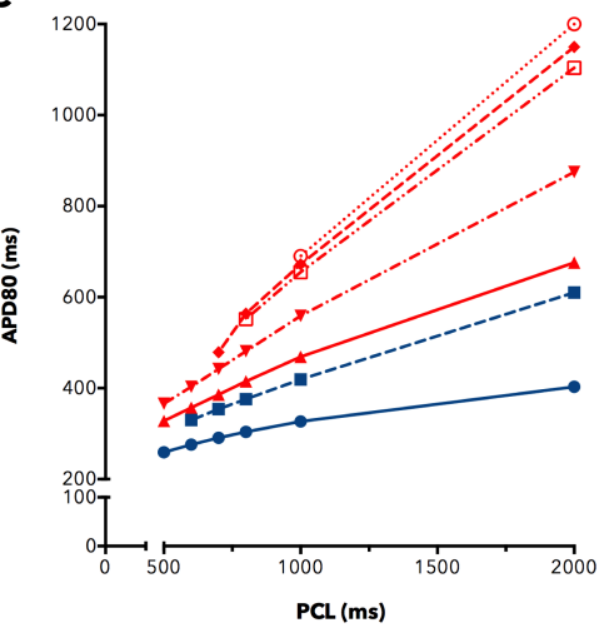

E

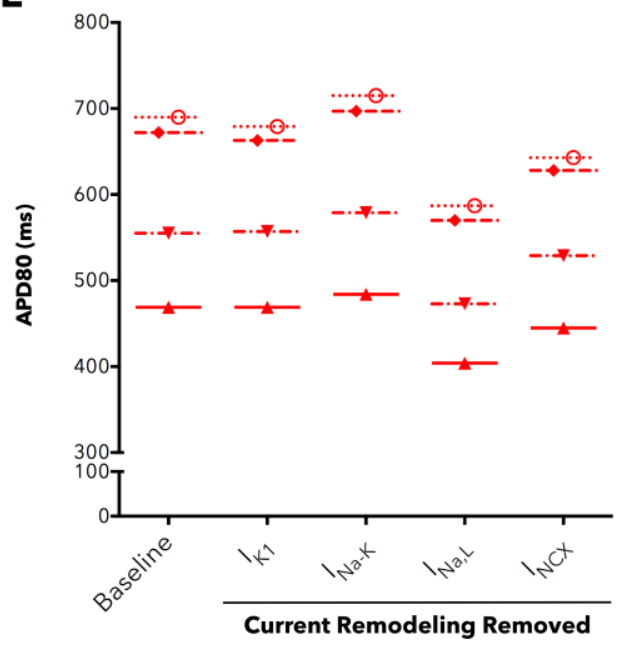

D

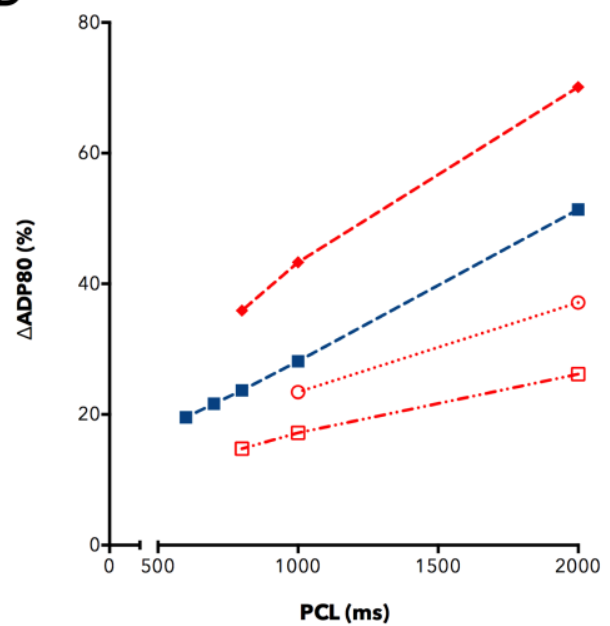

F

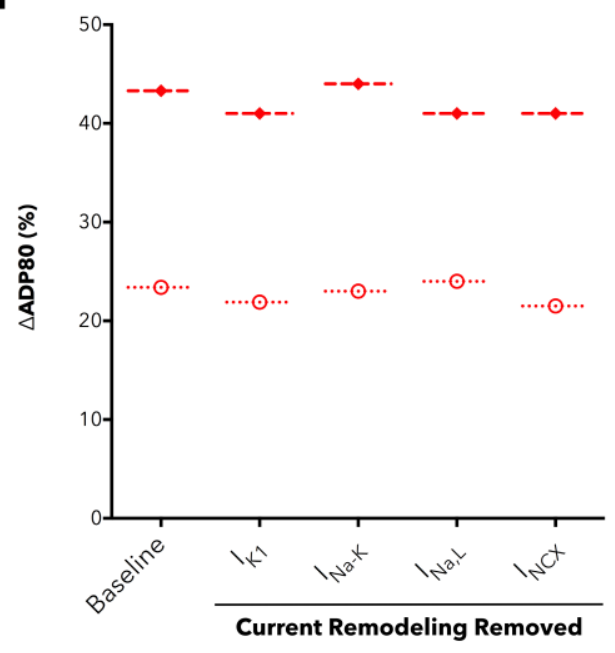


The experimentally determined $\triangle A P D 80$ shows that the relative APD80 prolongation is greater in donor compared with failing myocytes. Thus, in order to reproduce experimental results, we carried out 250 systematic cellular simulations for different PCLs with different degrees of block by E-4031 in nonfailing 251 and failing myocytes, taking into account HF-induced $\mathrm{I}_{\mathrm{kr}}$ downregulation (Supplementary Figure S6).

252 Figure 5A,B show color-coded maps of APD80 prolongation (relative to $100 \%$ ), which is more

253 pronounced in the case of nonfailing myocytes for different PCLs and different degrees of drug-induced 254 block, than in the case of $\mathrm{HF}$ with $50 \% \mathrm{I}_{\mathrm{kr}}$ downregulation. Figure $5 \mathrm{C}$ shows restitution curves for failing 255 and nonfailing simulations with or without $I_{k r}$ drug block. Simulated APD80 values at low PCLs are not 256 reported because of repolarization failure in the HF model. Figure 5D illustrates the corresponding drug257 induced APD80 increase with respect to baseline in both failing and nonfailing conditions. Our 258 simulations qualitatively reproduce experimental results provided that the model of $\mathrm{HF}$ includes $\mathrm{I}_{\mathrm{Kr}}$ 259 remodeling, i.e. a 50\% downregulation in the cases illustrated in the two lower curves in Figure 5D. If $\mathrm{I}_{\mathrm{Kr}}$ 260 downregulation was not included in the HF model, APD80 increase with drug was much more 261 pronounced than in normal myocytes. These results confirm our hypothesis that $\mathrm{I}_{\mathrm{kr}}$ is downregulated in $262 \mathrm{HF}$, to a similar degree as determined by our experimental protein expression studies. To further 263 examine the role that other currents play in AP prolongation due to $\mathrm{I}_{\mathrm{kr}}$ blockade, we repeated 264 simulations at $\mathrm{PCL}=1000 \mathrm{~ms}$, while removing the $\mathrm{HF}$ remodeling of other important currents, including $265 I_{\mathrm{K} 1}, I_{\mathrm{Na}-\mathrm{K}}, I_{\mathrm{Na}, \mathrm{L}}$, and $I_{\mathrm{NCX}}$. When these currents were not remodeled, APD80 values were altered before and 266 after drug block (Figure 5E), thus impacting the $\triangle$ APD80 for each condition (Figure 5F). However, with 267 the removal of remodeling of any currents in the HF model, $\triangle A P D 80$ values were very similar to the HF 268 model with just $50 \% \mathrm{I}_{\mathrm{kr}}$ reduction. Also, in each case, the $\triangle \mathrm{APD} 80$ values are smaller than with the $\mathrm{HF}$ 269 model without $I_{\mathrm{kr}}$ downregulation, suggesting that $\mathrm{I}_{\mathrm{kr}}$ downregulation is key to replicating the 270 experimental $\triangle A P D 80$ trend.

272 Multicellular simulation of $I_{k r}$ blockade. The results obtained in the multicellular strand simulations show 273 a similar tendency: $I_{\mathrm{kr}}$ remodeling was required in the HF model to obtain a lesser $\triangle$ APD80 compared 274 with nonfailing myocytes. Several cases of homogeneous and heterogeneous remodeling were 275 considered. Figure 6A shows an illustrated schematic of our simulated 1D multicellular strand, with 276 cones marking the endocardial and epicardial cells, which were used for measurements. Endocardial 277 (upper panels) and epicardial (lower panels) APs are depicted for baseline and under the effects of E2784031 for nonfailing (Figure 6B,D; cells \#50 and \#150, respectively) and for failing (Figure 6C, E; cells \#50 279 and \#150, respectively). APD prolongation is greater in nonfailing myocytes than in failing myocytes. 
Figure 6F shows nonfailing and failing restitution curves from endocardial and epicardial cells of the strand with simulated blockade by E-4031. Simulated APD80 values at low PCLs are not reported

282 because of repolarization failure in the $\mathrm{HF}$ model. Note that $\mathrm{E}-4031$ reduces $\mathrm{I}_{\mathrm{kr}}$ activity by $90 \%$ in 283 nonfailing tissue and by $70 \%$ in failing tissue. $\triangle$ APD80 caused by E-4031 is slightly more pronounced in 284 the nonfailing tissue, as illustrated in Figure 6G. These results corroborate our experimental findings.

285 Also, the $\triangle A P D 80$ values shown are greater in endocardium than in epicardium for both nonfailing and 286 failing conditions. This effect is intrinsic to basic GPB model (see Figure 7B in Grandi et al.,[14]), where endocardial cells are more sensitive to $\mathrm{I}_{\mathrm{Kr}}$ block than epicardial cells. In our HF model this effect is even more evident because $I_{\mathrm{Kr}}$ downregulation was more pronounced in epicardial cells than in endocardial cells, rendering the endocardium more responsive to $\mathrm{I}_{\mathrm{kr}}$ block.

A
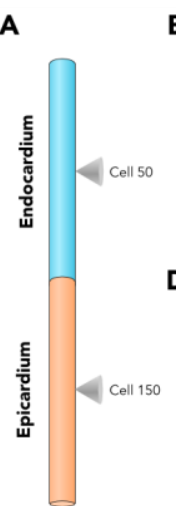

292

293

294

295

296

297

298

299

300

301

302

303

304

\section{Discussion}
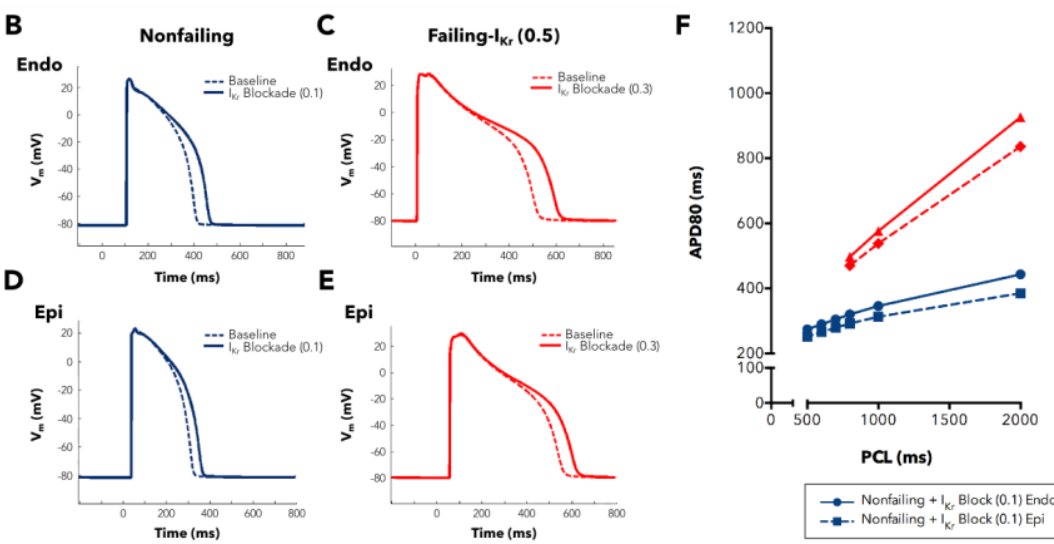

$\mathrm{PCl}(\mathrm{ms})$

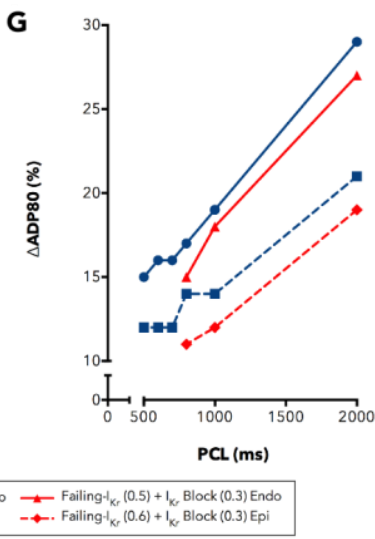

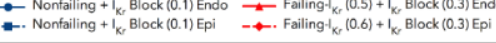

Our results demonstrate functional downregulation of the E-4031 sensitive $\mathrm{I}_{\mathrm{Kr}}$ current in the failing human heart, which may contribute to repolarization abnormalities and arrhythmogenesis in HF. While we observe a clear functional downregulation of $I_{\mathrm{Kr}}$ in the failing $L V$, these changes are not associated with gene expression changes for $h E R G 1 a$ or $h E R G 1 b$. We posit that the lack of decreased $h E R G 1 a$ or $h E R G 1 b$ gene expression suggests transcriptional regulation of $I_{\mathrm{Kr}}$ is not a homeostatic mechanism in end-stage human HF, i.e. to preserve contractile force through AP prolongation, and this may contribute to the relatively small observed APD differences in failing compared with donor human hearts. Although gene expression is unaltered, we have demonstrated protein expression changes for hERG1a and hERG1b. Thus, we speculate that post-translational modifications and targeting of hERG channels may be the most critical factors governing $I_{\mathrm{kr}}$ functional expression in failing human heart. Likewise, previous 
studies have demonstrated that cell surface expression of Connexin43 and Cav1.2 are reduced in human

306 HF due to impaired trafficking.[25, 26] Protein expression levels and post-translational effects on hERG1, 307 resulting from general disruption in cardiomyocyte architecture and cellular trafficking in $\mathrm{HF}$, are likely

308 important regulators of $\mathrm{I}_{\mathrm{kr}}$ levels.

Alterations of hERG1 expression levels and stoichiometry underlie APD changes. Our results suggest that

311 functional downregulation may be due to disruption of the cell surface protein expression (mature

312 hERG1a), with contribution of a stoichiometric shift between hERG1a:hERG1b at the protein level.

313 Larsen et al.[12] have shown greater levels of hERG1a than hERG1b in the human heart. Thus,

314 decrements in hERG1a protein may have a greater influence on overall $\mathrm{I}_{\mathrm{kr}}$ levels. However, the shift in

315 stoichiometry of hERG1a:hERG1b is due to a reduction in both mature and immature isoforms of

316 hERG1a, combined with an increased trend in hERG1b.

317 Though the expression of the hERG1b isoform in the human heart has been somewhat

318 controversial, with one report showing detection of the $h E R G 1 b$ transcript while another showed no

319 hERG1b protein expression.[9, 12] However, the most critical demonstration of hERG1b function in the

320 human heart was from Sale et al.[27], who identified the first long QT-linked mutation specifically within

$321 h E R G 1 b$. Our study is the first report of hERG1b in human cardiac tissue at both the transcript and

322 protein levels; however, we acknowledge the difficulty in obtaining results for hERG1b protein

323 expression from human cardiac tissue. Often, both hERG1a and hERG1b proteins were difficult to detect

324 via Western blot. We primarily attribute this to the process for development and validation of

325 antibodies, which are typically only tested against overexpressed hERG proteins in heterologous

326 expression systems. Thus, when attempting to probe in human cardiac tissue, the low level of hERG1

327 protein relative to other cellular proteins makes detection challenging. We attempted to use several

328 antibodies from various companies including Abcam, Alomone Labs, Cell Signaling Technology, Enzo Life

329 Sciences, and Santa Cruz Biotechnology. Several of the antibodies yielded considerable non-specific

330 binding; thus, we did not consider these results to be interpretable or accurate. Ultimately, we observed

331 the sharpest results for hERG1a and hERG1b expression with the antibody from Alomone Labs, and

332 confirmed specific hERG1b expression with the hERG1b antibody from Enzo Life Sciences

333 (Supplementary Figure S4).

335 Optical imaging of $L V$ wedge preparations versus an isolated cell approach. In many experimental 336 systems, whole-cell voltage clamp is the gold standard for measuring functional channel cell surface 
expression,[28-30] and $\mathrm{I}_{\mathrm{kr}}$ has been successfully recorded in isolated cardiomyocytes from undiseased

338 human hearts.[31, 32] However, we have not used cell isolation and patch-clamp methods for several

339 reasons. Delayed-rectifier current levels are small in cardiomyocytes, because these channels operate

340 on the portion of the AP where membrane resistance is high; thus minor changes in $\mathrm{K}^{+}$current flux lead

341 to large changes in membrane potential.[33] The amplitude of representative $\mathrm{I}_{\mathrm{kr}}$ tail current in human

342 cardiac myocytes was shown to be $\sim 50 \mathrm{pA}$, which contrasts with other human cardiac ion currents that

343 are hundreds of $\mathrm{pAs}$ to $\mathrm{nAs}$ in amplitude, such as $\mathrm{I}_{\mathrm{Na}}$ or $\mathrm{I}_{\mathrm{K} 1} \cdot[31,32] \mathrm{In}$ addition, the cell isolation process

344 has been shown to specifically disrupt the membrane expression of delayed rectifier $\mathrm{K}^{+}$channels. This

345 effect should be particularly pronounced for the digestion of human myocardium, which requires harsh

346 digestion conditions due to the high level of fibrotic tissue, especially in failing hearts. Presumably, due

347 to the combination of these effects, Beuckelmann and colleagues were unable to analyze delayed-

348 rectifier $\mathrm{K}^{+}$currents in isolated cells from donor or failing hearts. In this study, delayed-rectifier currents

349 were either small or non-existent, which prohibited comparison between groups.[2, 34] Thus, due to the

350 relatively small amplitude of $\mathrm{I}_{\mathrm{kr}}$ in even nondiseased human cardiomyocytes, and the variability in

351 current amplitude demonstrated by Beuckelmann et al.[2], we concluded that differences $\mathrm{I}_{\mathrm{kr}}$ between

352 donor and failing heart populations would be difficult to reliably detect without prohibitively large

353 sample numbers.

354 Instead, we have relied on changes in APD following $\mathrm{I}_{\mathrm{Kr}}$ blockade to serve as an indicator for

355 functional expression. Although the E-4031 blocker utilized is highly specific for $I_{k r}$, we recognize that our

356 approach does not completely isolate the effects of this single current on $\triangle A P D$. Cardiac APs are the

357 composite of dynamic responses from many currents, and, thus, $\triangle A P D s$ from blocking $\mathrm{I}_{\mathrm{kr}}$ cannot be

358 solely attributed to the density of $\mathrm{I}_{\mathrm{Kr}}$. Simulation studies using multivariate correlation analysis of $\triangle A P D$

359 from $\mathrm{I}_{\mathrm{kr}}$ blockade show that $\mathrm{I}_{\mathrm{kr}}$ conductance is the most strongly (positively) associated model

360 parameter, but that many other parameters are also correlated with $\triangle A P D .[35,36]$ These other

361 parameters include conductances and kinetics of many ion channels, such as $I_{K 1}, I_{\mathrm{Ks}}$ and $I_{\mathrm{Na}, \mathrm{L}}$, which may

362 be positively or negatively associated with $\triangle A P D$ from $I_{k r}$ blockade. However, the added power of our

363 approach is the ability to obtain AP recordings from many cells within tissue, and from different

364 transmural regions; thus, providing additional information that more closely approximates the behavior

365 in the intact human heart. We also consider the magnitude of the experimental effect to be quite

366 profound, with 70\% increase in APD80 after $\mathrm{I}_{\mathrm{kr}}$ blockade in donor compared with only $\sim 30 \%$ increase in

367 failing hearts. This large experimental difference supports that a reduction in $\mathrm{I}_{\mathrm{kr}}$ conductance is a major

368 contributing factor to the differential response to $\mathrm{I}_{\mathrm{kr}}$ blockade in donor versus failing hearts. 
Optical mapping of LV wedge preparations has also enabled us to confirm other aspects of EP remodeling in the failing human heart that have formerly been reported by our group. We have previously found transmural gradients in APD to be reduced in failure [3, 4, 23, 37], which we also observed in this study. In two preparations, we also identified some tissue areas that would have been labeled as $\mathrm{M}$ cell islands by the definition used in Glukhov et al.[23]

Reduced $\triangle A P D 80$ s in failing and the Law of Initial Values. Our results also indicate that the reduced percent increase in APD following $I_{\mathrm{Kr}}$ blockade is not due to the Law of Initial Value (LIV),[38, 39] which would assert that the reduced $\triangle A P D 80$ s in failing are due to higher baseline values. Although, the underlying mechanism for a LIV effect is unknown, the prolonged APs in failing would be closer to a theoretical APD upper limit. Following $\mathrm{I}_{\mathrm{kr}}$ blockade, not only was $\triangle \mathrm{APD} 80$ greater for donor hearts, but also the absolute duration of APs was greater compared with failing hearts, further suggesting functional $I_{\mathrm{kr}}$ downregulation in failure.

$I_{K r}$ downregulation in HF computational models. Our computer simulations qualitatively reproduced the experimental $I_{\mathrm{kr}}$ downregulation. As stated above, there was previously no experimental evidence of $\mathrm{I}_{\mathrm{Kr}}$ downregulation in the failing human heart, and results of delayed rectifier current expression from animal models of HF are strikingly inconsistent. Tsuji and colleagues found that, in the rabbit pacinginduced HF model, both E-4031-sensitive and -resistant components were significantly smaller than those in control hearts. [40] In addition, decreased activity of the delayed rectifier current was observed in ventricular myocytes obtained from cats with hypertrophy.[41] In contrast, studies of isolated myocytes from the pressure overload guinea pig or spontaneously hypertensive rat models documented no change in $I_{\mathrm{Kr}}$. Likewise, $I_{\mathrm{kr}}$ also remained unchanged in canine models of HF.[42] $[43,44]$ Thus, in

392 previous simulation studies, $I_{\mathrm{kr}}$ downregulation has not been incorporated in computational HF models, 393 regardless of species.[45-47] Only Walmsley et al.[17] considered $\mathrm{I}_{\mathrm{Kr}}$ downregulation in their HF 394 computer model on the basis of our group's previous experimental findings on gene expression changes 395 in HF.[11] Our simulations illustrate for the first time that $\mathrm{I}_{\mathrm{Kr}}$ downregulation must be incorporated in $\mathrm{HF}$ 396 remodeling to obtain a smaller E-4031-induced APD80 prolongation than in nonfailing conditions, as 397 obtained experimentally in the present study.

398 Another aspect shown in our simulations and in previous computational studies, is that $\mathrm{I}_{\mathrm{kr}}$ block399 induced APD prolongation does not only depend on the amount of $\mathrm{I}_{\mathrm{kr}}$ but also on the amount of other 400 currents conductance (see Figure 6F). Similarly, a computational study based on Luo and Rudy dynamic 
model (Luo and Rudy 1994) by Saiz et al. (Saiz et al., 2011) obtained different APD prolongations with

402 the same dose of dofetilide in endocardial, epicardial, and $\mathrm{M}$ cells, which present differences in $\mathrm{I}_{\mathrm{Ks}}$ 403 conductance. Also Brennan et al. (Brennan et al., 2009) used TNNP (Ten Tusscher 2006) model and 404 obtained different APD prolongations with sotalol in the different ventricular cells having different Ito 405 and $\mathrm{I}_{\mathrm{Ks}}$ conductances. Finally, Mirams et al. (Mirams et al., 2011) highlighted the importance of including 406 three (instead of $\mathrm{I}_{\mathrm{Kr}}$ only) ion-channel effects to the predictive classification of drugs into the risk 407 categories established by Redfern (Redfern et al., 2003). They suggested that AP modeling of multiple 408 ion-channel effects may improve early identification of clinical risk and that torsadogenic effects of hERG 409 block can be eliminated by inhibiting additional channels. Although it is important to take into account 410 that $I_{\mathrm{Kr}}$ block-induced APD prolongation is affected by other ion currents, we can conclude from our 411 simulations that $\mathrm{I}_{\mathrm{Kr}}$ downregulation leads to lower $\mathrm{I}_{\mathrm{kr}}$ block-induced APD prolongations than in the 412 absence of $\mathrm{I}_{\mathrm{kr}}$ downregulation. Indeed, as demonstrated the simulation studies by Britton et al. (Britton 413 et al., 2013) and Sarkar et al. (Sarkar et al., 2011), $\mathrm{I}_{\mathrm{kr}}$ conductance is the ionic parameter which affects 414 the most APD prolongation after drug induced $\mathrm{I}_{\mathrm{kr}}$ block, much more than other ion channel 415 conductances. Also the sensitivity analyses performed by O'hara et al. (O'Hara et al., 2011) and 416 Walmsley et al. (Walmsley et al., 2013) showed that $\mathrm{I}_{\mathrm{kr}}$ downregulation had a bigger effect on APD 417 prolongation than remodeling of other ion currents in control conditions. This held for failing myocytes 418 (Walmsley et al., 2013).

Limitations

Our protocol required the use of blebbistatin in order to acquire APs free of motion artifact.

423 Blebbistatin has been previously shown not to affect electrophysiology in multiple species, including 424 humans. [48] In addition, because we work with human tissue, we take hearts for study as they become 425 available; thus, we have a varied and uncontrolled population in comparison to animal models research. 426 There are other important factors upon which we are unable to perfectly match our donor and failing 427 heart groups, including age and gender.

428 Our computer myocyte model for HF, based on changes in the ion channel parameters, has the 429 inherited limitations described in Trenor et al.[15] Mainly, data from a large number of experimental 430 studies were taken into account, thus resulting in a high variability not only in the ionic remodeling but 431 also in the stage and etiology of HF and its phenotype. This computer model was validated against 432 experimental data of $\mathrm{AP}$ and $\mathrm{Ca}^{2+}$ transient measurements in human failing hearts. APD prolongation in 
$433 \mathrm{HF}$ was $43 \%$ using the baseline HF model; this value is within the experimental range[45, 49]. In the

434 present study, when $I_{\mathrm{kr}}$ downregulation was also included in the HF model, APD prolongation was more 435 pronounced (70\%). The experimental studies by Beuckelman et al.[2, 50] also reported a pronounced 436 APD increase (60-67\%) in HF.[2, 50] Given the existent experimental variability in HF measurements, 437 various combinations of ion current remodeling values would yield a HF phenotype within experimental 438 ranges. In this way, the simulation study by Walmsley et al.[17] considers a polulation of HF models to 439 account for the experimental variability.

440 It is also to be noted that the baseline GPB model has an APD80 within experimental ranges taken 441 from other studies, but significantly shorter than the experimental measurements shown in the present 442 work. The absolute APD80 values simulated with our HF model also present significant differences with 443 our experimental measurements. The comparison between experiments and simulations should not be 444 strictly quantitative but rather qualitative, given the high experimental variability. We would like to 445 highlight again that these simulations are a proof of concept rather than a strict reproduction of the 446 experimental quantitative results.

447 In spite of its inherent limitations, the HF model utilized in the present study provides valid proof448 of-concept and reinforcement of our experimental findings.

\section{Figure Legends}

455 Figure 1. Experimental methodology. A. Posterolateral image of a human heart. Black dashed box 456 outlines marginal artery territory for wedge preparation, and black arrowheads indicate two descending 457 marginal arteries. B. Representative wedge preparation image with paired optical (blue) and 458 microelectrode (red) recordings. Wedge transmural regions separated by dashed lines, and black and 459 red arrows highlight pacing and microelectrodes, respectively. C. Timeline of the experimental protocol. 460 A=aorta; Epi=epicardium; Endo=endocardium; LA=left atrium; LV=left ventricle; RA=right atrium;

$461 \quad \mathrm{RV}=$ right ventricle.

463 Figure 2. APD80 restitution before and after $\mathrm{I}_{\mathrm{Kr}}$ blockade. Restitution curves for the pacing cycle length $464(P C L)$ versus APD80 for A. donor $(n=7)$ and $D$. failing $(n=4)$ hearts at baseline, demonstrating greater 465 transmural APD80 dispersion for donor hearts and higher APD80s for failing hearts. APD80 restitution 
curves for B. donor and $\mathbf{E}$. failing hearts after $I_{\mathrm{Kr}}$ blockade with E-4031. In contrast to the baseline

467 conditions, absolute APD80 values are now greater in donor compared with failing hearts. APD80 468 gradients (APD80 Endo - APD80 $_{\text {Epi }}$ ) at several PCLs for C. baseline and F. E-4031 conditions. Data are expressed as mean \pm SEM.

Figure 3. $\triangle A P D 80$ values with $\mathrm{I}_{\mathrm{kr}}$ blockade. A-B. Representative APD80 maps, optical recording traces, and pseudo-ECGs for donor and failing hearts. Gaussian distribution curves calculated from means and pooled standard deviations of APD80 values for C. donor and D. failing hearts. E. Average APD80 values

474 for donor $(n=7)$ and failing $(n=4)$ hearts under control and E-4031 conditions recorded at 1000 ms pacing 475 cycle length (PCL). F. $\triangle$ APD80s, expressed as a \% of control for $1000 \mathrm{~ms}$ PCLs. Data are expressed as 476 mean \pm SEM.

Figure 4. hERG1 gene and protein expression levels. Graphs with individual data points showing $h E R G 1 a$ A. and $h E R G 1 b$ B. gene expression is not different between donor $(n=8)$ and failing $(n=8)$ human hearts. Box and whisker plots of total hERG1a C. and mature hERG1a D. relative to GAPDH show that failing $(n=5)$ compared with donor $(n=6)$ heart hERG1a levels trend toward reduction. Graphs demonstrating total E. and mature F. hERG1b protein expression levels are unchanged. G. Graph showing significantly decreased hERG1a:hERG1b protein in the failing epicardium. H. Representative Western blot image. Bar graphs show data expressed as mean \pm SEM. Boxes show median, $25 \%$ percentile, and $75 \%$ percentile, and whiskers indicate the minimum and maximum of the distribution.

Figure 5. Cellular simulation results. A,B. Color-coded maps of APD increase (relative to 100\%) in nonfailing myocytes and failing myocytes with $\mathrm{I}_{\mathrm{kr}}$ blockade. The results are shown for different pacing cycle lengths (PCLs, $x$-axis) and for different degrees of drug block ( $y$-axis). The model of HF considers $I_{k r}$ downregulation by 0.5 . C. APD80 restitution curves for nonfailing, failing, and failing with $\mathrm{I}_{\mathrm{Kr}}$ downregulation myocytes with and without $\mathrm{I}_{\mathrm{kr}}$ blockade. D. $\triangle \mathrm{APD} 80 \mathrm{~s}$ with $\mathrm{I}_{\mathrm{kr}}$ blockade ( $90 \%$ or $\left.70 \%\right)$,

492 expressed as a \% of control in a nonfailing cell and in failing cells with or without $\mathrm{I}_{\mathrm{kr}}$ downregulation. $\mathbf{E}$.

493 APD80 values plus and minus $\mathrm{I}_{\mathrm{kr}}$ blockade for failing cells with and without $\mathrm{I}_{\mathrm{kr}}$ downregulation at $\mathrm{PCL}=$

$4941000 \mathrm{~ms}$. Baseline APD80 values and values after removal of $\mathrm{HF}$ remodeling for $I_{\mathrm{K} 1}, I_{\mathrm{Na}-\mathrm{K}}, I_{\mathrm{Na}, \mathrm{L}}$, and $I_{\mathrm{NCX}}$ are

495 displayed. F. $\triangle$ APD80s after $I_{\mathrm{kr}}$ blockade for failing myocytes with and without $\mathrm{I}_{\mathrm{kr}}$ downregulation are

496 shown for baseline conditions and after removing remodeling for $I_{K 1}, I_{N a-K}, I_{N a, L}$, and $I_{N C X}$ in the $H F$ 497 simulations. 
Figure 6. Multicellular strand simulations. A. Illustrated schematic of the multicellular strand for

500 simulations, including endocardial and epicardial cells and cones marking the cells used for

501 measurement. B. Nonfailing and C. failing endocardial myocyte APs before and after $\mathrm{I}_{\mathrm{kr}}$ blockade with E-

5024031 (cell \#50). D. Nonfailing and E. failing epicardial myocytes APs before and after $I_{\mathrm{kr}}$ blockade with E-

5034031 (cell \#150). F. APD80 restitution curves of cells \#50 (endocardium) and \#150 (epicardium) for

504 nonfailing and failing conditions. Drug blockade was $90 \%$ in nonfailing cells and $70 \%$ in failing cells. G.

$505 \triangle$ APD80s expressed as a \% of control in cells \#50 (endocaridum) and \#150 (epicardium) for nonfailing

506 and failing conditions under $\mathrm{I}_{\mathrm{kr}}$ blockade with E-4031. Drug blockade was $90 \%$ in nonfailing cells and $70 \%$

507 in failing cells.

509 Table 1. Demographic characteristics of donor and failing hearts used for optical imaging analysis.

510 CVA=cerebrovascular accident; $D=$ donor; $F=$ failing; $I C H=$ intracerebral hemorrhage; ICM=ischemic

511 cardiomyopathy; MVA=motor vehicle accident; NICM=nonischemic cardiomyopathy.

\begin{tabular}{|c|c|c|c|}
\hline$D / F$ & Age & Gender & $\begin{array}{c}\text { Diagnosis/ } \\
\text { Cause of Death }\end{array}$ \\
\hline$D$ & 17 & $\mathrm{~F}$ & MVA \\
\hline$D$ & 37 & $\mathrm{~F}$ & CVA \\
\hline$D$ & 39 & $M$ & $\mathrm{ICH}$ \\
\hline$D$ & 52 & $M$ & MVA \\
\hline $\mathrm{D}$ & 58 & M & CVA \\
\hline$D$ & 60 & $M$ & CVA \\
\hline$D$ & 65 & $M$ & CVA \\
\hline $\mathrm{F}$ & 44 & $\mathrm{~F}$ & NICM \\
\hline$F$ & 55 & M & ICM \\
\hline$F$ & 57 & M & ICM \\
\hline$F$ & 59 & $\mathrm{~F}$ & NICM \\
\hline
\end{tabular}


514 Table 2. Detailed ionic current modifications to GPB model for failing cardiac myoctes. These model 515 manipulations were previously published in Trenor et al.[15]

516

\begin{tabular}{|c|c|c|}
\hline $\begin{array}{l}\text { Parameter } \\
\text { modified }\end{array}$ & $\begin{array}{c}\% \text { of change respect original } \\
\text { GPB model[14] }\end{array}$ & References \\
\hline $\mathrm{I}_{\mathrm{NaL}}$ & $\uparrow 200$ & $\begin{array}{l}\text { Valdivia et al. 2005.[7], } \\
\text { Maltsev et al. 2007.[51] }\end{array}$ \\
\hline$\tau_{\mathrm{NaL}}$ & $\uparrow 200$ & Maltsev et al. 2007.[51], \\
\hline $\mathrm{I}_{\text {to }}$ & $\downarrow 60$ & $\begin{array}{c}\text { Beuckelmann et al. 1993.[2], } \\
\text { Wettwer et al. 1994.[52], } \\
\text { Nabauer et al. 1996.[53] }\end{array}$ \\
\hline $\mathrm{I}_{\mathrm{K} 1}$ & $\downarrow 32$ & $\begin{array}{l}\text { Beuckelmann et al. 1993.[2], } \\
\text { Tomaselli and Marban. 1999.[54], } \\
\text { Li et al. 2004.[49] }\end{array}$ \\
\hline $\mathrm{I}_{\mathrm{NaK}}$ & $\downarrow 10$ & $\begin{array}{c}\text { Bundgaard et al. 1996.[55], } \\
\text { Tomaselli and Marban. 1999.[54], } \\
\text { Tomaselli and Zipes. 2004.[1] }\end{array}$ \\
\hline$I_{\mathrm{Nab}}$ & $=0$ & Priebe and Beuckelmann. 1998.[45] \\
\hline $\mathrm{I}_{\mathrm{Cab}}$ & 个153 & Priebe and Beuckelmann. 1998.[45] \\
\hline $\mathrm{I}_{\mathrm{NCX}}$ & 个175 & Priebe and Beuckelmann. 1998.[45] \\
\hline $\mathrm{I}_{\mathrm{SERCA}}$ & $\downarrow 50$ & $\begin{array}{l}\text { Hasenfuss et al. 1994.[56], } \\
\text { Schwinger et al. 1995.[57], } \\
\text { Piacentino et al. 2003.[20] }\end{array}$ \\
\hline $\mathrm{I}_{\text {leak }}$ & $\uparrow 500$ & Bers et al. 2006.[58] \\
\hline $\mathrm{EC}_{50 \mathrm{SR}}$ & $\downarrow 11$ & $\begin{array}{l}\text { Bers et al. 2006.[58], } \\
\text { Antoons et al. 2007.[59], } \\
\text { Curran et al. 2010.[60] }\end{array}$ \\
\hline
\end{tabular}


None

\section{Acknowledgements}

We thank the Translational Cardiovascular Biobank \& Repository (TCBR) at Washington University for provision of donor/patient records. The TCBR is supported by the NIH/CTSA (UL1 TR000448), Children's Discovery Institute, and Richard J. Wilkinson Trust. We also thank the laboratory of Dr. Sakiyama-Elbert for the use of the StepOnePlus equipment. We appreciate the critical feedback on the manuscript by Dr. Jeanne Nerbonne. This work has been supported by the National Heart, Lung \& Blood Institute (NHLBI, R01 HL114395). K. Holzem has been supported by the American Heart Association (12PRE12050315) and the NHLBI (F30 HL114310).

\section{References}

[1] Tomaselli GF, Zipes DP. What causes sudden death in heart failure? Circ Res. 2004;95:75463.

[2] Beuckelmann DJ, Nabauer M, Erdmann E. Alterations of $K+$ currents in isolated human ventricular myocytes from patients with terminal heart failure. Circ Res. 1993;73:379-85. [3] Glukhov AV, Fedorov VV, Kalish PW, Ravikumar VK, Lou Q, Janks D, et al. Conduction Remodeling in Human End-Stage Non-Ischemic Left Ventricular Cardiomyopathy. Circulation. 2012.

[4] Lou Q, Fedorov VV, Glukhov AV, Moazami N, Fast VG, Efimov IR. Transmural heterogeneity and remodeling of ventricular excitation-contraction coupling in human heart failure. Circulation. 2011;123:1881-90.

[5] Akar FG, Rosenbaum DS. Transmural electrophysiological heterogeneities underlying arrhythmogenesis in heart failure. Circ Res. 2003;93:638-45.

[6] Maltsev VA, Sabbah HN, Higgins RS, Silverman N, Lesch M, Undrovinas AI. Novel, ultraslow inactivating sodium current in human ventricular cardiomyocytes. Circulation. 1998;98:2545-52.

550 [7] Valdivia CR, Chu WW, Pu J, Foell JD, Haworth RA, Wolff MR, et al. Increased late sodium current in myocytes from a canine heart failure model and from failing human heart. J Mol Cell

553 channel in normal and failing human myocardium. J Mol Cell Cardiol. 2002;34:1477-89.

556 and human heart. Trends Cardiovasc Med. 2001;11:286-94. 
[10] Laughner JI, Ng FS, Sulkin MS, Arthur RM, Efimov IR. Processing and analysis of cardiac optical mapping data obtained with potentiometric dyes. American Journal of Physiology-Heart and Circulatory Physiology. 2012;303:H753-H65. [11] Ambrosi CM, Yamada KA, Nerbonne JM, Efimov IR. Gender differences in electrophysiological gene expression in failing and non-failing human hearts. PLoS One. 2013;8:e54635. [12] Larsen AP, Olesen SP, Grunnet M, Jespersen T. Characterization of hERG1a and hERG1b potassium channels-a possible role for hERG1b in the I (Kr) current. Pflugers Arch. 2008;456:1137-48.

[13] Livak KJ, Schmittgen TD. Analysis of relative gene expression data using real-time quantitative PCR and the 2-[Delta][Delta] CT method. Methods. 2001;25:402-8.

[14] Grandi E, Pasqualini FS, Bers DM. A novel computational model of the human ventricular action potential and Ca transient. J Mol Cell Cardiol. 2010;48:112-21.

[15] Trenor B, Cardona K, Gomez JF, Rajamani S, Ferrero Jr JM, Belardinelli L, et al.

Simulation and mechanistic investigation of the arrhythmogenic role of the late sodium current in human heart failure. PloS one. 2012;7:e32659.

[16] Soltysinska E, Olesen S-P, Christ T, Wettwer E, Varró A, Grunnet M, et al. Transmural expression of ion channels and transporters in human nondiseased and end-stage failing hearts. Pflügers Archiv-European Journal of Physiology. 2009;459:11-23.

[17] Walmsley J, Rodriguez JF, Mirams GR, Burrage K, Efimov IR, Rodriguez B. mRNA expression levels in failing human hearts predict cellular electrophysiological remodeling: A population-based simulation study. PLoS One. 2013;8:e56359.

[18] Xiong W, Tian Y, DiSilvestre D, Tomaselli GF. Transmural heterogeneity of Na+-Ca2+ exchange evidence for differential expression in normal and failing hearts. Circ Res. 2005;97:207-9.

[19] Gomez JF, Cardona K, Romero L, Ferrero Jr JM, Trenor B. Electrophysiological and Structural Remodeling in Heart Failure Modulate Arrhythmogenesis. 1D Simulation Study. PloS one. 2014;9:e106602.

[20] Piacentino V, 3rd, Weber CR, Chen X, Weisser-Thomas J, Margulies KB, Bers DM, et al. Cellular basis of abnormal calcium transients of failing human ventricular myocytes. Circ Res. 2003;92:651-8.

[21] Reinecke H, Studer R, Vetter R, Holtz J, Drexler H. Cardiac Na+/Ca2+ exchange activity in patients with end-stage heart failure. Cardiovasc Res. 1996;31:48-54.

[22] Iyer V, Heller V, Armoundas AA. Altered spatial calcium regulation enhances electrical heterogeneity in the failing canine left ventricle: implications for electrical instability. J Appl Physiol. 2012;112:944-55.

[23] Glukhov AV, Fedorov VV, Lou Q, Ravikumar VK, Kalish PW, Schuessler RB, et al. Transmural dispersion of repolarization in failing and nonfailing human ventricle. Circ Res. 2010;106:981-91.

[24] Abi- Gerges N, Holkham H, Jones E, Pollard C, Valentin JP, Robertson G. hERG subunit composition determines differential drug sensitivity. Br J Pharmacol. 2011;164:419-32.

[25] Smyth JW, Hong TT, Gao D, Vogan JM, Jensen BC, Fong TS, et al. Limited forward trafficking of connexin 43 reduces cell-cell coupling in stressed human and mouse myocardium. The Journal of clinical investigation. 2010;120:266-79. 
[26] Hong TT, Smyth JW, Chu KY, Vogan JM, Fong TS, Jensen BC, et al. BIN1 is reduced and

602 Cav1.2 trafficking is impaired in human failing cardiomyocytes. Heart rhythm : the official

603 journal of the Heart Rhythm Society. 2012;9:812-20.

604 [27] Sale H, Wang J, O'Hara TJ, Tester DJ, Phartiyal P, He JQ, et al. Physiological properties of $605 \mathrm{hERG} 1 \mathrm{a} / 1 \mathrm{~b}$ heteromeric currents and a hERG $1 \mathrm{~b}$-specific mutation associated with Long-QT 606 syndrome. Circ Res. 2008;103:e81-95.

607 [28] Baroudi G, Pouliot V, Denjoy I, Guicheney P, Shrier A, Chahine M. Novel mechanism for 608 Brugada syndrome: defective surface localization of an SCN5A mutant (R1432G). Circ Res. 609 2001;88:E78-83.

610 [29] Furutani M, Trudeau MC, Hagiwara N, Seki A, Gong Q, Zhou Z, et al. Novel mechanism 611 associated with an inherited cardiac arrhythmia: defective protein trafficking by the mutant 612 HERG (G601S) potassium channel. Circulation. 1999;99:2290-4.

613 [30] Krumerman A, Gao X, Bian JS, Melman YF, Kagan A, McDonald TV. An LQT mutant 614 minK alters KvLQT1 trafficking. American journal of physiology Cell physiology.

615 2004;286:C1453-63.

616 [31] Iost N, Virag L, Opincariu M, Szecsi J, Varro A, Papp JG. Delayed rectifier potassium 617 current in undiseased human ventricular myocytes. Cardiovasc Res. 1998;40:508-15.

618 [32] Magyar J, Iost N, Körtvély Á, Banyasz T, Virag L, Szigligeti P, et al. Effects of endothelin6191 on calcium and potassium currents in undiseased human ventricular myocytes. Pflügers 620 Archiv. 2000;441:144-9.

621 [33] Nerbonne JM, Kass RS. Molecular physiology of cardiac repolarization. Physiol Rev. $622 \quad 2005 ; 85: 1205-53$.

623 [34] Veldkamp MW, van Ginneken AC, Opthof T, Bouman LN. Delayed rectifier channels in 624 human ventricular myocytes. Circulation. 1995;92:3497-504. [35] Britton OJ, Bueno-Orovio A, Van Ammel K, Lu HR, Towart R, Gallacher DJ, et al. Experimentally calibrated population of models predicts and explains intersubject variability in cardiac cellular electrophysiology. Proc Natl Acad Sci U S A. 2013;110:E2098-E105. [36] Sarkar AX, Sobie EA. Quantification of repolarization reserve to understand interpatient variability in the response to proarrhythmic drugs: A computational analysis. Heart Rhythm. 2011;8:1749-55.

[37] Ng FS, Holzem KM, Koppel AC, Janks D, Gordon F, Wit AL, et al. Adverse Remodeling of the Electrophysiological Response to Ischemia-Reperfusion in Human Heart Failure Is Associated With Remodeling of Metabolic Gene Expression. Circulation: Arrhythmia and Electrophysiology. 2014;7:875-82.

[38] Hord DJ, Johnson LC, Lubin A. Differential effect of the law of initial value (LIV) on autonomic variables. Psychophysiology. 1964;1:79-87.

[39] Tu YK, Gilthorpe MS. Revisiting the relation between change and initial value: a review and evaluation. Stat Med. 2007;26:443-57.

[40] Tsuji Y, Opthof T, Kamiya K, Yasui K, Liu W, Lu Z, et al. Pacing-induced heart failure causes a reduction of delayed rectifier potassium currents along with decreases in calcium and transient outward currents in rabbit ventricle. Cardiovasc Res. 2000;48:300-9.

[41] Furukawa T, Bassett A, Furukawa N, Kimura S, Myerburg R. The ionic mechanism of reperfusion-induced early afterdepolarizations in feline left ventricular hypertrophy. J Clin Invest. 1993;91:1521. 
[42] Li GR, Lau CP, Ducharme A, Tardif JC, Nattel S. Transmural action potential and ionic current remodeling in ventricles of failing canine hearts. American journal of physiology Heart and circulatory physiology. 2002;283:H1031-41. [43] Brooksby P, Levi AJ, Jones JV. Investigation of the mechanisms underlying the increased contraction of hypertrophied ventricular myocytes isolated from the spontaneously hypertensive rat. Cardiovasc Res. 1993;27:1268-77.

[44] Ahmmed GU, Dong PH, Song G, Ball NA, Xu Y, Walsh RA, et al. Changes in Ca2+ cycling proteins underlie cardiac action potential prolongation in a pressure-overloaded guinea pig model with cardiac hypertrophy and failure. Circ Res. 2000;86:558-70.

\section{Circ Res. 1998;82:1206-23.}

[46] Moreno JD, Zhu ZI, Yang P-C, Bankston JR, Jeng M-T, Kang C, et al. A computational model to predict the effects of class I anti-arrhythmic drugs on ventricular rhythms. Science translational medicine. 2011;3:98ra83-98ra83.

[47] Zhang Y, Shou G, Xia L. Simulation study of transmural cellular electrical properties in failed human heart. Engineering in Medicine and Biology Society, 2005 IEEE-EMBS 2005 27th Annual International Conference of the: IEEE; 2006. p. 337-40.

\section{[48] Fedorov VV, Lozinsky IT, Sosunov EA, Anyukhovsky EP, Rosen MR, Balke CW, et al.} Application of blebbistatin as an excitation-contraction uncoupler for electrophysiologic study of rat and rabbit hearts. Heart rhythm : the official journal of the Heart Rhythm Society. 2007;4:619-26.

[49] Li GR, Lau CP, Leung TK, Nattel S. Ionic current abnormalities associated with prolonged action potentials in cardiomyocytes from diseased human right ventricles. Heart Rhythm. 2004;1:460-8.

[50] Beuckelmann DJ, Erdmann E. Ca(2+)-currents and intracellular [Ca2+]i-transients in single ventricular myocytes isolated from terminally failing human myocardium. Basic Res Cardiol. 1992;87 Suppl 1:235-43.

[51] Maltsev VA, Silverman N, Sabbah HN, Undrovinas AI. Chronic heart failure slows late sodium current in human and canine ventricular myocytes: Implications for repolarization variability. European Journal of Heart Failure. 2007;9:219-27.

[52] Wettwer E, Amos GJ, Posival H, Ravens U. Transient outward current in human ventricular myocytes of subepicardial and subendocardial origin. Circ Res. 1994;75:473-82.

[53] Nabauer M, Beuckelmann DJ, Uberfuhr P, Steinbeck G. Regional differences in current density and rate-dependent properties of the transient outward current in subepicardial and subendocardial myocytes of human left ventricle. Circulation. 1996;93:168-77.

[54] Tomaselli GF, Marban E. Electrophysiological remodeling in hypertrophy and heart failure. Cardiovasc Res. 1999;42:270-83.

[55] Bundgaard H, Kjeldsen K. Human myocardial Na,K-ATPase concentration in heart failure. Mol Cell Biochem. 1996;163-164:277-83.

[56] Hasenfuss G, Reinecke H, Studer R, Meyer M, Pieske B, Holtz J, et al. Relation between myocardial function and expression of sarcoplasmic reticulum $\mathrm{Ca}(2+)$-ATPase in failing and nonfailing human myocardium. Circ Res. 1994;75:434-42.

[57] Schwinger RH, Böhm M, Schmidt U, Karczewski P, Bavendiek U, Flesch M, et al. Unchanged protein levels of SERCA II and phospholamban but reduced $\mathrm{Ca} 2+$ uptake and $\mathrm{Ca} 2+-$ ATPase activity of cardiac sarcoplasmic reticulum from dilated cardiomyopathy patients compared with patients with nonfailing hearts. Circulation. 1995;92:3220-8. 
691 [58] Bers DM, Despa S, Bossuyt J. Regulation of $\mathrm{Ca} 2+$ and $\mathrm{Na}+$ in normal and failing cardiac 692 myocytes. In: Sideman S, Beyar R, Landesberg A, editors. Interactive and Integrative 693 Cardiology2006. p. 165-77.

694 [59] Antoons G, Oros A, Bito V, Sipido KR, Vos MA. Cellular basis for triggered ventricular 695 arrhythmias that occur in the setting of compensated hypertrophy and heart failure:

696 considerations for diagnosis and treatment. J Electrocardiol. 2007;40:S8-S14.

697 [60] Curran J, Brown KH, Santiago DJ, Pogwizd S, Bers DM, Shannon TR. Spontaneous Ca 698 waves in ventricular myocytes from failing hearts depend on Ca2+-calmodulin-dependent 699 protein kinase II. J Mol Cell Cardiol. 2010;49:25-32.

700 